\title{
MATERIALS FOR THE STUDY OF STEEL AND OF STEEL GUNS.
}

\author{
BY D. CHERNOFE.
}

Translated by Dr. William Anderson, F.R.S., Vice-Presment'; AND PUBLISHED BY THE AUTHORITY OF THE COUNCIL.

[The following remarks, made by the author in the discussion on 23 Nov. 1868 upon his paper "On the Manufacture of Steel, and the mode of Working it," have been translated from the Proceedings of the Imperial Russian Technical Society, having been accidentally discovered only recently by the translator, by whom the loan of a rare copy was procured with some difficulty.]

Mr. Chernoff reviewed the principal points raised in his paper "On the Manufacture of Steel, and the mode of Working it" (Proceedings Inst. Mech. E. 1880, page 286), and expressed his opinion that the tenacity of the same piece of steel varied between very wide limits depending on the structure of the specimen; and that, if it were desired to compare two samples of steel, the comparison should be made only when it was certain that the two specimens were in the same condition with respect to internal structure. The more a crystalline structure predominated, the less tough would the steel be, and the lower would be its quality. In addition, he expressed his opinion that the tenacity of a piece of steel of given internal structure would be the same, by whatever means that structure was obtained, whether by forging or otherwise. The greater or less extent to which crystals are developed depends upon the slower or quicker rate of cooling of the steel from a temperature higher than that at which it changes to the amorphous structure; and also upon the greater or less nearness with which that higher temperature approaches the point of fusion. 
In support of these conclusions, Mr. Chernoff referred to the results which he had obtained in the testing of various samples of steel; and he submitted two additional specimens prepared from the same piece of steel in the following manner. A round bar, $3 \frac{1}{4}$ inches diameter by 8 inches long, was heated uniformly to a bright red (orange) heat, and was then reduced by forging throughout its length to $1 \frac{1}{2}$ inch diameter; the forging was completed while the steel was still at a light red heat, and the bar was allowed to cool gradually in dry sand. When cold it was broken in two, and one half was treated in the following manner. It was heated to a temperature a little higher than $b$ on Chernoff's scale, Fig. 1, Plate 106 (see also Proceedings 1880, page 290); in this scale $b$ is the temperature below which if steel be heated it does not change its structure in cooling, whether cooled slowly or quickly. The heated piece was then at once plunged into water, from which it was withdrawn at a dull red heat, and allowed to cool in dry sand. Specimens were then cut from each half of the original bar, and tested for tensile resistance.

The first specimen, from the forged but untreated half, was 5.8 inches long by 0.8 inch diameter; the load first applied was 4,680 lbs., and was increased by twelve increments of $3,120 \mathrm{lbs}$. up to 42,120 lbs., which was safely carried; but when the next increment was added, the specimen broke, having stretched uniformly throughout its length. Assuming that the load of 42,120 lbs. finally carried without breaking indicated the ultimate strength, this would amount to nearly 38 tons per square inch, with an elongation of $7 \cdot 07$ per cent.; and the dynamic resistance of a cubic inch was about $1 \cdot 3$ inch-tons.

The second specimen, taken from the forged and treated half of the bar, was 6.3 inches long by 0.8 inch diameter. The lording being carried out in the same way as with the first specimen, 57,720 lbs. were lifted safely, and the specimen broke asunder at the next increment. Just before fracture a contraction took place about the middle of the length of the specimen. Supposing that $57,720 \mathrm{lbs}$. was the ultimate strength, this is equivalent to 52 tons per square inch. The elongation was $7 \cdot 7$ per cent., and therefore the dynamic resistance per cubic inch was nearly 2 inch-tons. 
On the strength of these and similar investigations, Mr. Chernoff proposed to try, on a 4-pounder gun, the principle of bringing steel to the amorphous condition and then cooling it quickly down to a certain point, hoping by this means to increase its resisting power; and thus to enable a lot of 4-pounder guns, which had been rejected for insufficient strength, to pass proof satisfactorily. In order to form an estimate of the probable effect of this treatment, he communicated the results of some former experiments with the 4-pounder guns.

Muzzle-loading guns Nos. 24 and 44, 3.37 inches calibre, $7 \cdot 85$ inches external diameter, steel shot about $12 \frac{1}{2}$ lbs. weight, windage 0.03 inch :-

Gun No. 24 .
2 rounds.
1
2 ",
Gun burst.

$\begin{array}{cl}\text { Gun No. } 44 . & \text { Charge. } \\ 1 \text { round. } & 1 \cdot 35 \text { lbs. } \\ 2 \quad, \quad & 1 \cdot 8 \quad, \\ 1 \quad \text { " } & 2 \cdot 7 \quad, \\ \text { Gun burst. } & \end{array}$

As it was thought that the smallness of the windage was the chief cause of the destructive effect of a 2.7 lbs. charge, the proof of the further guns was made with cast-iron shot about $12 \cdot 15$ lbs. weight, surrounded with zinc bands, $3 \cdot 2$ inches diameter.

Gun No. 28. 10 rounds, $1 \cdot 35$ los. charge.

$\begin{array}{lllll}5 & & 1 \cdot 8 & & \\ 5 & \Rightarrow & 2 \cdot 25 & \\ 1 & \Rightarrow & 2 \cdot 475 & \end{array} \quad$ Gun burst.

Before the final boring out, this gun had been hardened by means of cold water inside the bore; but in the hardening no attention had been paid to Mr. Chernoff's investigations, and to the essential principles involved in the process: that is, the temperature $b$ had not been reached in the heated steel. The treatment had actually injured the material, inasmuch as the gun did not withstand even the 2.475 lbs. charge; and, as Mr. Chernoff supposes, had not merely left the original coarsely crystalline structure, but had added to it a certain degree of hardening which still further reduced the tenacity.

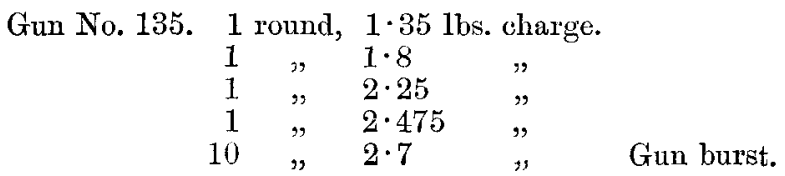


Gun No. 138. The external diameter was made 1 inch larger than that of the others:-

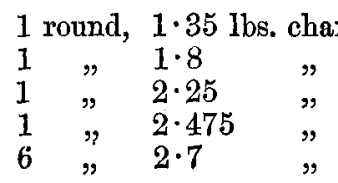

In consequence of the considerable increase in the diameter of the bore, the experiment was stopped.

Gun No. 142. 1 round, $1 \cdot 35$ lbs. charge.

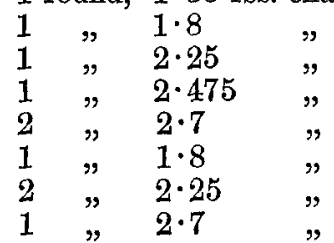

The experiment was stopped on account of the enlargement of the bore by $6 \frac{1}{2}$ hundredths of an inch.

Gun No. 139. 1 round, $1 \cdot 35$ lbs. charge.

$$
\begin{array}{lllll}
1 & & 1 \cdot 8 & & \\
1 & \# & 2 \cdot 25 & \# & \\
1 & \# & 2 \cdot 475 & & \\
6 & \Rightarrow & 2 \cdot 7 & &
\end{array}
$$

Gun No. 56 before finishing was annealed and hardened :-

$$
\begin{array}{ll}
1 \text { round, } & 1 \cdot 35 \text { lbs. charge. } \\
1 & 1 \cdot 8 \quad \% \quad \text { Gun burst. } \\
1 & 2 \cdot 25 \quad \% \quad \text {. }
\end{array}
$$

The fractured surfaces showed that the temperature $b$ had not been reached; while the boring out proved that the temperature $a$ had been exceeded, as it had been in gun No. 28 , because the material had hardened. The temperature $a$ on Chernoff's scale is below $b$, and is such that steel, however hard it may be, will not harden if heated to a temperature lower than $a$, however quickly it is cooled, Fig. 1, Plate 106.

Gun No. 6. The breech had been strengthened by means of three steel hoops, shrunk on with a shrinkage of 0.03 inch :- 
2 rounds, $1 \cdot 35$ lbs. charge.

$\begin{array}{llll}2 & & 1 \cdot 8 & \\ 1 & \prime & 2 \cdot 25 & \\ 1 & \prime & 2 \cdot 475 & \\ 6 & \Rightarrow & 2 \cdot 7 & \end{array}$

Further proof was stopped because the bore had enlarged by 6 hundredths of an inch, and the first ring from the breech end had cracked and opened 1-8th inch.

Guns Nos. 18 and 21 were handed over to Mr. Chernoff to treat as he pleased. They were heated to a temperature rather higher than $b$, and then quickly cooled to a temperature lower than $b$, and then allowed to cool slowly in dry sand. Firing proof gave the following results.

Gun No. 18, outside diameter $7 \cdot 85$ inches, diameter of bore 3.41 inches, diameter of shot 3.2 inches; the windage round the body of the shot was therefore somewhat greater than in the rest of the guns, but on the other hand the bands which encircled 0.63 of the circumference of the shot had the same amount of windage as in the other guns:-

$$
\begin{aligned}
& 5 \text { rounds, } 1 \cdot 35 \text { lbs. charge. } \\
& 1,1 \cdot 8 \text { " } \\
& 1 \% 2 \cdot 25 \quad \text {, } \\
& 1 \% 2 \cdot 475 \text { " } \\
& 21 \% 2 \cdot 7 \quad \text { " } \\
& 1 \% 3 \cdot 15 \quad \text { " " } \\
& 20 \% 3 \cdot 6 \quad \text { " } \\
& 5 \text { " } 3 \cdot 6 \quad \text { " double shotted. }
\end{aligned}
$$

The diameter of the bore at a distance of 50 inches from the muzale had increased by $4 \frac{1}{4}$ hundredths of an inch.

Gun No. 21, external diameter $7 \cdot 75$ inches, bore $3 \cdot 364$ inches :-

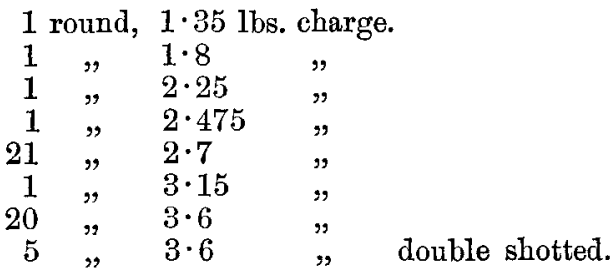


The diameter of the bore at a distance of 50 inches from the muzzle had increased by $5 \frac{1}{8}$ hundredths of an inch.

Mr. Chernoff exhibited several specially prepared specimens intended to illustrate characteristic periods in the working of steel : as for example, several specimens of cast but unforged steel, of which one specimen was especially remarkable for the strong development of a crystalline structure, arising from very slow cooling in the crucible inside the furnace; also a specimen of unforged steel of crystalline structure, and a fragment of the same piece in which the amorphous condition had been preserved by rapid cooling, the fracture appearing in consequence finely crystalline. Several specimens of forged cast-steel were also shown.

Mr. Chernoff explained that his process had been carried out with a furnace of special construction, shown in section in Fig. 2, Plate 106, into which the gun was let down in a vertical position by a crane, and deposited on its breech end upon an annular chair C. The furnace was itself sunk in the ground near the crane, and had an annular grate $G$ at bottom, with an aperture $A$ for firing and for setting the breech of the gun in its place upon the ring $R$ on the top of the chair $\mathrm{C}$. Numerous sight-holes $\mathrm{S}$ enabled the progress of heating to be watched. The flue F passed off to the chimney; and a sheet-iron cover $\mathrm{V}$ closed the top of the furnace while in operation. Before receiving the gun, the furnace was heated to redness; while the gun also was gently warmed beforehand, till it had attained a temperature of about $300^{\circ} \mathrm{C}$. or $572^{\circ} \mathrm{Fahr}$. at the breech end. The gun was then lowered into the furnace, and raised to a red heat; and was then withdrawn, and lowered, still in a vertical position, into an iron tank O, Fig. 3, filled with olive oil. The oil tank was itself immersed in a larger tank $W$, through which a current of cold water was made to circulate from the inlet pipe $I$ at bottom to the overflow trough $T$ at top. The gun did not remain in the oil more than half a minute, so as to avoid too rapid cooling and consequent hardening, the object being merely to reduce the steel to a temperature below $b$, and by that means to retain its amorphous 
structure. The gun came out of the oil at a dark red heat, and was buried in dry sand in order that it might cool slowly, so as to avoid internal stresses; the cooling might safely be slow, because below the temperature $b$ steel is incapable of undergoing any molecular change. In order to permit the oil to circulate through the bore while the gun was submerged in the oil tank, Fig. 3 , the breech end had drilled through it axially a hole $2 \frac{1}{4}$ inches diameter, which was afterwards closed by a cascable screw.

Mr. Chermoff added some remarks on the forging of steel, and the effects which he considered were produced by the process. The necessity for forging an ingot of gun steel arose from the circumstance that it was not as yet known how to make sound steel castings. The castings usually had internal cavities arising from contraction, and on their external surfaces were formed an immense number of gas bubbles, which constituted a porous envelope. It was consequently necessary to cast the ingot much shorter and thicker than required for the gun, and then to close up the cavities and draw them out under the hammer. By this operation the internal hollows as well as the external porosities became elongated and attenuated, so that it was easier to remove them by subsequent boring and turning. It might therefore be said that forging would have to be retained, until it had been learnt how to produce absolutely sound castings. 
STEEL GUNS

Fig.1. Chernoff's scale

for Steel Temperature.

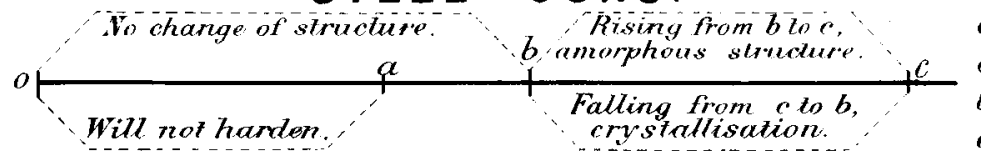

0 zero of serete

Plale 106

crystalisation.

$a$ rurk oherniz red.

red, but not sparkling.

c) nelting point.

Fig. 2. Verlical Section
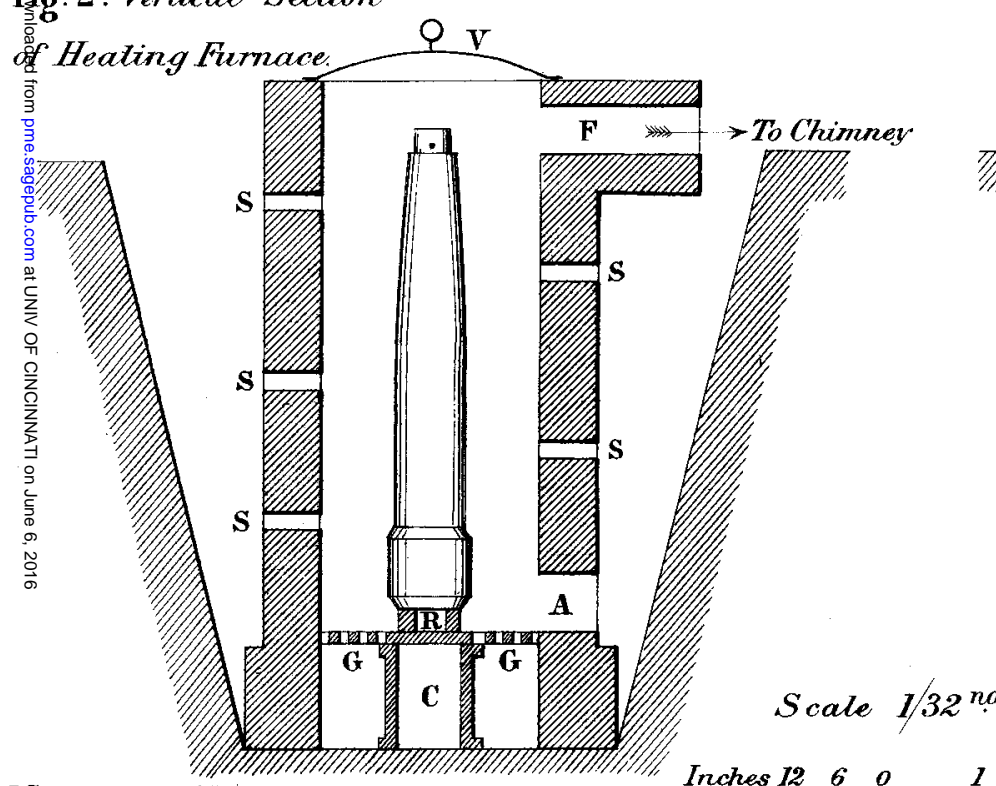

F $>$ To Chimney
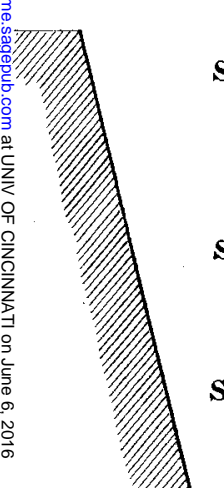

(1)

Mechanical Engineens 1891 .

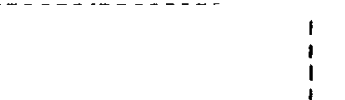

Fig. 3. Vertical Section of Cooling Tank.

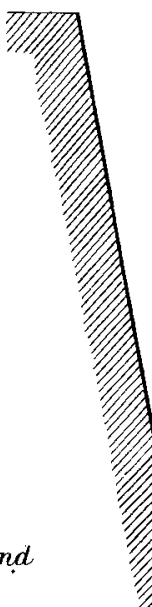

2
3 'PlPll:

4 PIPIT:S

5 'IPIII)

PIPIIII 